\title{
Patients with Helicobacter pylori-positive gastric cancer with human cytomegalovirus infection have a low tendency of advanced lymphatic metastasis in a Chinese population
}

\author{
$\mathrm{CHAO} \mathrm{CHEN}^{1 *}$, SIAN CHEN $^{2 *}$, ZHENG HAN $^{2 *}$, WANGKAI XIE ${ }^{2}$, TEMING ZHANG ${ }^{2}, \mathrm{CHENCHEN} \mathrm{MAO}^{2}$, \\ LIANG ZHANG ${ }^{2}$, XIANGWEI SUN ${ }^{2}$, TERRY KWOK ${ }^{3-6}$, XIAN SHEN $^{2}$ and XIANGYANG XUE ${ }^{7}$ \\ ${ }^{1}$ Department of Oncology, Wenzhou Hospital of Integrated Traditional Chinese and Western Medicine Affiliated to \\ Zhejiang Chinese Medical University; ${ }^{2}$ Department of General Surgery, The Second Affiliated Hospital and \\ Yuying Children's Hospital of Wenzhou Medical University, Wenzhou, Zhejiang 325000, P.R. China; \\ ${ }^{3}$ Infection and Immunity Program; ${ }^{4}$ Cancer Program, Biomedicine Discovery Institute; Departments of ${ }^{5}$ Biochemistry \\ and Molecular Biology, and ${ }^{6}$ Microbiology, Monash University, Melbourne, Victoria 3800, Australia; \\ ${ }^{7}$ Department of Microbiology and Immunology, Institute of Molecular Virology and Immunology, \\ Institute of Tropical Medicine, School of Basic Medical Science, Wenzhou Medical University,
}

Wenzhou, Zhejiang 325000, P.R. China

Received September 14, 2019; Accepted July 22, 2020

DOI: $10.3892 / \mathrm{ol} .2021 .12663$

\begin{abstract}
Recognized as a group I carcinogen for gastric cancer (GC) and a factor involved in the development of GC, Helicobacter pylori serves a major part in GC research. However, most studies have focused on $H$. pylori itself, ignoring the complicated pathogenic microbiological environment of GC and neglecting the synergistic or antagonistic effects of $H$. pylori with other pathogenic microorganisms. Increasing evidence has revealed that the human cytomegalovirus (HCMV) is present in several types of tumors and serves an important role in the neoplastic process of certain human malignant tumors, including GC. The aim of the present study was to explore the role of HCMV and $H$. pylori co-infection in GC. HCMV and H. pylori infection was analyzed in paired
\end{abstract}

Correspondence to: Professor Xian Shen, Department of General Surgery, The Second Affiliated Hospital and Yuying Children's Hospital of Wenzhou Medical University, 109 West Xueyuan Road, Wenzhou, Zhejiang 325000, P.R. China

E-mail: 13968888872@163.com

Professor Xiangyang Xue, Department of Microbiology and Immunology, Institute of Molecular Virology and Immunology, Institute of Tropical Medicine, School of Basic Medical Science, Wenzhou Medical University, 7 Zhongxin North Road, Higher Education Park, Chashan Street, Wenzhou, Zhejiang 325000, P.R. China

E-mail: wzxxy001@163.com

*Contributed equally

Key words: human cytomegalovirus, lymphatic metastasis, Helicobacter pylori, co-infection, gastric cancer gastric tumor and peri-tumoral tissues from 134 (98 male and 36 female) patients using PCR. The results revealed that a total of $74(55.2 \%)$ patients had H. pylori infection, 58 patients $(43.3 \%)$ had HCMV infection, and $34(25.4 \%)$ patients had both HCMV and H. pylori infection. Univariate and multivariate analyses demonstrated that $H$. pylori infection was independently associated with advanced lymphatic metastasis $[\mathrm{P}=0.007$; odds ratio $(\mathrm{OR})=3.51]$. Furthermore, compared with $\mathrm{HCMV}^{-} / H$. pylori $i^{-}$, neither $\mathrm{HCMV}^{+} / H$. pylori nor $\mathrm{HCMV}^{+} / H$. pylori ${ }^{+}$were associated with metastasis, but $\mathrm{HCMV}^{-} / H$. pylori ${ }^{+}$co-infection status was an independent risk factor for advanced lymphatic metastasis $(\mathrm{P}=0.005$; $\mathrm{OR}=6.00)$. In conclusion, GC co-infected with HCMV and $H$. pylori exhibited a low tendency of lymph node metastasis. HCMV may interact with $H$. pylori to inhibit the process of lymphatic metastasis, and the mechanism requires further investigation.

\section{Introduction}

Gastric cancer (GC) is one of the most common malignant neoplasms of the upper gastrointestinal tract in Asia, with an incidence rate of 64.6 per 100,000 individuals in 2012 and exhibiting substantial mortality (1). Gastric oncogenesis is a multistep process, involving non-atrophic gastritis, atrophic gastritis, intestinal metaplasia, dysplasia and eventually GC (2). The exact factors involved in the occurrence and development of GC are not yet fully understood, with the exception of Helicobacter pylori infection. H. pylori is a Gram-negative bacteria that is strongly associated with GC occurrence, and it has been recognized as a group I carcinogen by the International Agency for Research on Cancer in 1994 (3). Furthermore, the chronic inflammation resulting from $H$. pylori infection is believed to be a major step in the initiation and development of GC (4). 
Despite the high incidence of $H$. pylori infection worldwide, only $1-3 \%$ of the $H$. pylori-infected individuals progress to $\mathrm{GC}$ (5), which suggests that other factors must be involved in GC etiology. Human cytomegalovirus (HCMV), a member of the herpesvirus family (6), is prevalent among the general population, with an infectious rate ranging between 50 and $100 \%$ (7). In the last two decades, HCMV has been reported to serve an important role in the neoplastic process of human malignant tumors, such as glioblastoma, salivary gland cancer, lung carcinoma, breast cancer, prostatic carcinoma, colorectal cancer and hepatocellular carcinoma (8-14). Our previous study revealed that HCMV was present in 50-69.61\% of GC tissues (15). However, only a few studies have focused on the effect of HCMV on GC. Previous studies have revealed a difference in the expression levels of the UL133, UL135, UL136 and UL138 genes between normal gastric and tumor tissues $(16,17)$. Additionally, an association between HCMV infection and lymphatic metastasis was observed in GC (15). Considering the high prevalence of $H$. pylori and its role in $\mathrm{GC}$, the synergetic or antagonistic effects between HCMV and $H$. pylori could not be ignored when investigating the role of HCMV in GC. Therefore, the present study aimed to detect the infection with HCMV and H.pylori in patients with GC using PCR and to explore the potential association between them in GC.

\section{Materials and methods}

Patients, specimens and data collection. A total of 134 patients (98 males and 36 females; age range, 31-89 years; median age, 68 years) who underwent elective gastrectomy for GC at The Second Affiliated Hospital of Wenzhou Medical University (Wenzhou, China) between January 2017 and January 2018 were included in the present study. Paired gastric tumor and peri-tumoral tissues $(\geq 10 \mathrm{~cm}$ from the negative reception margin) were collected. The histopathological diagnosis of gastric tumor and paired non-tumor specimens was confirmed following surgery by the pathological department of The Second Affiliated Hospital of Wenzhou Medical University. Once collected, specimens were deposited into tubes and preserved in liquid nitrogen immediately until further use. Patient clinicopathological data, including sex, age, tumor size (the longest tumor diameter), tumor location, general type (ulcer or non-ulcer), tumor invasion, lymphatic metastasis, TNM stage, vessel invasion (defined by the pathological department using hematoxylin and eosin staining according to routine hospital protocols) and differentiation, were collected prospectively. Tumor invasion, lymphatic metastasis and TNM stage were defined according to the National Comprehensive Cancer Network Gastric Cancer Guidelines version 3.2015 (18). The present study was approved by the Human Research Ethics Committee of The Second Affiliated Hospital of Wenzhou Medical University, and written informed consent was provided by all participants.

Genomic DNA extraction. Total genomic DNA was extracted from 134 pairs of tumor and peri-tumoral tissue samples using a QIAamp DNA mini kit (Tiangen Biotech Co., Ltd.) according to the manufacturer's protocol. DNA purity and concentration were quantified using a NanoDrop 1000 spectrophotometer (Thermo Fisher Scientific, Inc.). DNA samples were stored at $-20^{\circ} \mathrm{C}$ until further use.

Detection of H. pylori and HCMV infection. H. pylori and HCMV infections were determined by PCR. The primers for the $H$. pylori genes $16 \mathrm{~S}$ rRNA (19) and UreA (20), and for the HCMV genes UL47, UL56 and UL77 (15) are listed in Table I. GAPDH was used as an internal control. PCR was performed in a T100 ${ }^{\mathrm{TM}}$ Thermal Cycler (Bio-Rad Laboratories, Inc.). The PCR mixture contained 1X Taq MasterMix (Tiangen Biotech Co., Ltd.), $1 \mu \mathrm{g}$ DNA sample and $0.2 \mu \mathrm{M}$ each specific forward and reverse primers in a final volume of $25 \mu \mathrm{l}$. The positive controls for $H$. pylori and HCMV detection were DNA from a GC tissue resected from a patient clinically diagnosed with $H$. pylori infection at The Second Affiliated Hospital of Wenzhou Medical University and a clinically isolated HCMV strain or AD169 (American Type Culture Collection), respectively. The negative control was sterile double-distilled water. After an initial denaturation step at $95^{\circ} \mathrm{C}$ for $5 \mathrm{~min}$, the reaction mixtures were processed through 35 PCR cycles of denaturation at $95^{\circ} \mathrm{C}$ for $30 \mathrm{sec}$, annealing for $30 \mathrm{sec}$ at $58^{\circ} \mathrm{C}$ for UL47, UL56, UL77 and $16 \mathrm{~S}$ rRNA or $50^{\circ} \mathrm{C}$ for UreA, and extension at $72^{\circ} \mathrm{C}$ for $1 \mathrm{~min}$, followed by an additional extension step at $72^{\circ} \mathrm{C}$ for $10 \mathrm{~min}$. The final PCR products were loaded on a $1.2 \%$ agarose gel for electrophoresis, using GelRed for visualization. If a band was detected at the right size (according to the relative position of the band and marker) and the sequencing results (performed by The Beijing Genomics Institute) indicated the correct sequence, the gene was considered to be present in the tissue. If one of the two H. pylori genes or one of the three HCMV genes was effectively amplified, the tissue was considered positive for H. pylori or HCMV, respectively. Additionally, patients were considered to have $H$. pylori or HCMV infection if $H$. pylori or HCMV was detected in their gastric tissues, regardless of its presence in the tumor or adjacent peri-tumoral tissue.

Statistical analysis. Statistical analysis was performed using SPSS version 22.0 (IBM Corp.). Univariate analyses were performed using the $\chi^{2}$ test with Yates' correction or Fisher's exact test depending on the data type. Multivariate logistic regression analysis was performed to determine the independent risk factors. $\mathrm{P}<0.05$ was considered to indicate a statistically significant difference.

\section{Results}

Detection of H. pylori and HCMV infection. The results obtained using different primers exhibited good consistency (Fig. 1A). As aforementioned, patients were considered to have $H$. pylori or HCMV infection if $H$. pylori or HCMV were detected in their gastric tissues, regardless of its presence in the tumor or paired peri-tumoral tissue. Among the 134 patients, $H$. pylori was detected in 74 cases $(55.2 \%)$, including 52 cases positive only in peri-tumoral tissues and 22 cases positive in both tumor and peri-tumoral 
Table I. Primer information.

A, Helicobacter pylori

\begin{tabular}{llll}
\hline Gene & \multicolumn{1}{c}{ Forward primer $\left(5^{\prime} \rightarrow 3^{\prime}\right)$} & \multicolumn{1}{c}{ Reverse primer $\left(5^{\prime} \rightarrow 3^{\prime}\right)$} & Target size, bp \\
\hline 16S rRNA & CTTAACCATAGAACTGCATTTGAAACTAC & GGTCGCCTTCGCAATGAGTA & 119 \\
UreA & GCCAATGGTAAATTAGTT & CTCCTTAATTGTTTTTAC & 411 \\
\hline
\end{tabular}

B, Human cytomegalovirus

\begin{tabular}{llll}
\hline Gene & \multicolumn{1}{c}{ Forward primer $\left(5^{\prime} \rightarrow 3^{\prime}\right)$} & Reverse primer $\left(5^{\prime} \rightarrow 3^{\prime}\right)$ & Target size, bp \\
\hline UL47 & GTACAGCCCCACGTTCCTG & CCCGATACAGGTACTCGCGCT & 212 \\
UL56 & TCCTCCACGTCCTCCCCGTA & AGGCGCTGAGGGAGTACAAC & 202 \\
UL77 & GCACTTTTGATCGTCACGTGCT & ACGCAGATATTGCTGTTCGTGC & 215 \\
GAPDH & CAGGGCTGCTTTTAACTCTGGTAA & GGGTGGAATCATATTGGAACATGT & 101 \\
\hline
\end{tabular}

bp, base pair.

A

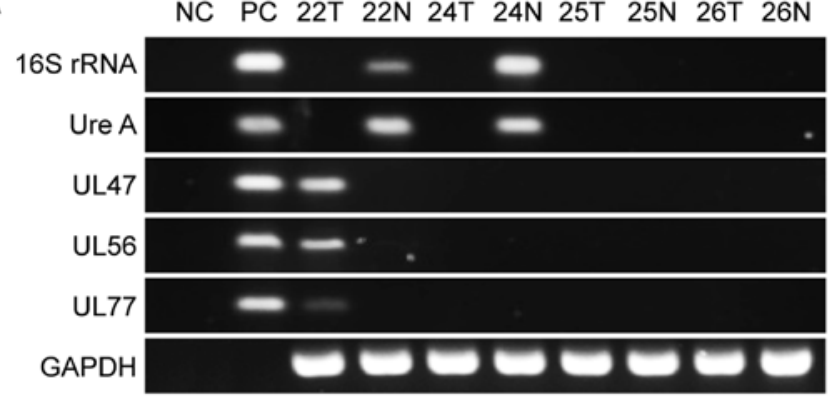

B
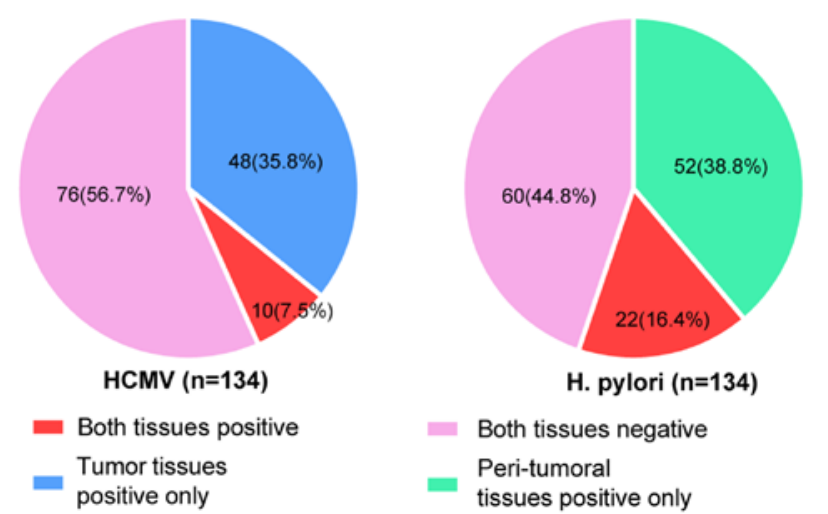

H. pylori $(n=134)$

- Both tissues negative

Peri-tumoral

tissues positive only

Figure 1. Detection of HCMV and H.pylori in gastric tissues from patients with gastric cancer. (A) PCR products after agarose gel electrophoresis. Numbers above the lanes represent tumor or peri-tumoral specimens of patients. The NC is double-distilled water, and the PC is DNA from a clinically confirmed $\mathrm{H}$. pylori ${ }^{+}$gastric tissue and a clinically isolated HCMV strain (AD169). GAPDH was used as an internal control. (B) Infection rates of HCMV and $\mathrm{H}$. pylori in 134 pairs of tissues from patients with gastric cancer. NC, negative control; PC, positive control; T, tumor specimen; $\mathrm{N}$, peri-tumoral specimen; HCMV, human cytomegalovirus; H. pylori, Helicobacter pylori.

tissues. HCMV infection was positive in 58 cases $(43.3 \%)$, comprising 48 cases positive only in tumor tissues and

Table II. Association between HCMV and H. pylori in gastric tumors.

\begin{tabular}{|c|c|c|c|c|c|}
\hline H.pylori status & Total & $\mathrm{HCMV}^{-}$ & $\mathrm{HCMV}^{+}$ & $\chi^{2}$ & P-value \\
\hline H.pylori ${ }^{-}$ & 60 & 36 & 24 & 0.477 & 0.490 \\
\hline H. pylori ${ }^{+}$ & 74 & 40 & 34 & & \\
\hline Total & 134 & 76 & 58 & & \\
\hline
\end{tabular}

HCMV, human cytomegalovirus; H. pylori, Helicobacter pylori.

10 cases positive in both tumor and peri-tumoral tissues (Fig. 1B). Both HCMV and H. pylori were detected in 34 cases $(25.4 \%)$; however, there was no significant association between HCMV and H. pylori infection $(\mathrm{P}=0.490$; Table II).

Associations between $H$. pylori infection and clinicopathological characteristics of patients with GC. Analysis of the clinicopathological characteristics revealed that patients in the H. pylori $^{+}$group exhibited a higher level of distant lymph node metastasis (N2 + N3) and TNM stage (T3 + T4), indicating that $H$. pylori infection status was significantly associated with lymphatic metastasis and TNM stage $(\mathrm{P}=0.013$ and $\mathrm{P}=0.023$, respectively). However, no significant associations were detected between $H$. pylori infection status and sex, age, tumor size, location, general type, invasion, vascular invasion or pathological differentiation $(\mathrm{P}>0.05$; Table III).

Association between HCMV infection and clinicopathological features of patients with GC. The analysis of HCMV infection and patient clinicopathological characteristics identified a significant negative association between HCMV infection status and lymphatic metastasis $(\mathrm{P}=0.002)$, as well as TNM stage $(\mathrm{P}=0.026)$. No significant associations were observed 
Table III. Clinicopathological features, H. pylori and HCMV infection in gastric tumors.

\begin{tabular}{|c|c|c|c|c|c|c|}
\hline \multirow[b]{2}{*}{ Clinicopathological feature } & \multicolumn{3}{|c|}{ H. pylori } & \multicolumn{3}{|c|}{ HCMV } \\
\hline & Negative, n (\%) & Positive, n (\%) & P-value & Negative, n (\%) & Positive, n (\%) & P-value \\
\hline Sex & & & 0.661 & & & 0.869 \\
\hline Female & $15(25.0)$ & $21(28.4)$ & & $20(26.3)$ & $16(27.6)$ & \\
\hline Male & $45(75.0)$ & $53(71.6)$ & & $56(73.7)$ & $42(72.4)$ & \\
\hline Agea, years & & & 0.464 & & & 0.692 \\
\hline$<68$ & $27(45.0)$ & $38(51.4)$ & & $38(50.0)$ & $27(46.6)$ & \\
\hline$\geq 68$ & $33(55.0)$ & $36(48.6)$ & & $38(50.0)$ & $31(53.4)$ & \\
\hline Tumor size, $\mathrm{cm}$ & & & 0.177 & & & 0.992 \\
\hline$<5$ & $37(61.7)$ & $37(50.0)$ & & $42(55.3)$ & $32(55.2)$ & \\
\hline$\geq 5$ & $23(38.3)$ & $37(50.0)$ & & $34(44.7)$ & $26(44.8)$ & \\
\hline Tumor location & & & $0.609^{\mathrm{b}}$ & & & $0.579^{\mathrm{b}}$ \\
\hline Antrum & $39(65.0)$ & $44(59.5)$ & & $46(60.5)$ & $37(63.8)$ & \\
\hline Corpus & $12(20.0)$ & $12(16.2)$ & & $15(19.7)$ & $9(15.5)$ & \\
\hline Cardia & $8(13.3)$ & $15(20.3)$ & & $14(18.4)$ & $9(15.5)$ & \\
\hline Diffuse & $1(1.7)$ & $3(4.1)$ & & $1(1.3)$ & $3(5.2)$ & \\
\hline General type & & & 0.690 & & & 0.806 \\
\hline Non-ulcer & $9(15.0)$ & $13(17.6)$ & & $13(17.1)$ & $9(15.5)$ & \\
\hline Ulcer & $51(85.0)$ & $61(82.4)$ & & $63(82.9)$ & $49(84.5)$ & \\
\hline Tumor invasion & & & 0.897 & & & 0.258 \\
\hline $\mathrm{T} 1+\mathrm{T} 2$ & $16(26.7)$ & $19(25.7)$ & & $17(22.4)$ & $18(31.0)$ & \\
\hline $\mathrm{T} 3+\mathrm{T} 4$ & $44(73.3)$ & $55(74.3)$ & & $59(77.6)$ & $40(69.0)$ & \\
\hline Lymphatic metastasis & & & $0.013^{\mathrm{c}}$ & & & $0.002^{\mathrm{c}}$ \\
\hline $\mathrm{N} 0+\mathrm{N} 1$ & $34(56.7)$ & $26(35.1)$ & & $25(32.9)$ & $35(60.3)$ & \\
\hline $\mathrm{N} 2+\mathrm{N} 3$ & $26(43.3)$ & 48 (64.9) & & $51(67.1)$ & $23(39.7)$ & \\
\hline TNM stage & & & $0.023^{\mathrm{c}}$ & & & $0.026^{\mathrm{c}}$ \\
\hline $\mathrm{I}+\mathrm{II}$ & $32(53.3)$ & $25(33.8)$ & & $26(34.2)$ & $31(53.4)$ & \\
\hline III+IV & $28(46.7)$ & $49(66.2)$ & & $50(65.8)$ & $27(46.6)$ & \\
\hline Vascular invasion & & & 0.332 & & & 0.706 \\
\hline No & $39(65.0)$ & $42(56.8)$ & & $47(61.8)$ & $34(58.6)$ & \\
\hline Yes & $21(35.0)$ & $32(43.2)$ & & $29(38.2)$ & $24(41.4)$ & \\
\hline Differentiation & & & $0.814^{\mathrm{b}}$ & & & $0.293^{\mathrm{b}}$ \\
\hline Well & $3(5.0)$ & $3(4.1)$ & & $3(3.9)$ & $3(5.2)$ & \\
\hline Moderate & $8(13.3)$ & $14(18.9)$ & & $9(11.8)$ & $13(22.4)$ & \\
\hline Poor & $35(58.3)$ & $43(58.1)$ & & $49(64.5)$ & $29(50.0)$ & \\
\hline Other & $14(23.3)$ & $14(18.9)$ & & $15(19.7)$ & $13(22.4)$ & \\
\hline
\end{tabular}

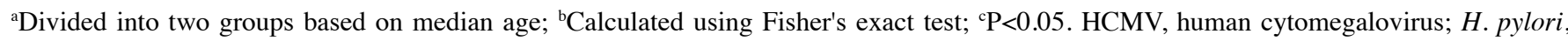
Helicobacter pylori.

between HCMV infection status and sex, age, tumor size, location, general type, invasion, vascular invasion or tumor differentiation $(\mathrm{P}>0.05$; Table III).

Clinical features of HCMV and $H$. pylori co-infection in patients with $G C$. The 134 patients were divided into $\mathrm{HCMV}^{+}$and $\mathrm{HCMV}^{-}$groups. In these groups, the patients were subdivided according to the presence or absence of $H$. pylori. Subgroup analysis revealed that in the $\mathrm{HCMV}^{+}$ group, H. pylori infection was not significantly associated with lymphatic metastasis $(\mathrm{P}=0.408)$, whereas in the $\mathrm{HCMV}^{-}$group, H. pylori infection was significantly associated with advanced lymphatic metastasis $(\mathrm{P}=0.003)$ and $\mathrm{TNM}$ stage $(\mathrm{P}=0.023)$. Tumor invasion exhibited no statistical significances between the two groups (Table IV).

Additionally, the 134 patients were divided into H. pylori ${ }^{+}$ and $H$. pylori $i^{-}$groups, which were further divided according to HCMV infection status. Subgroup analysis demonstrated that HCMV infection status was negatively associated with lymphatic metastasis $(\mathrm{P}<0.001)$ and $\mathrm{TNM}$ stage $(\mathrm{P}=0.026)$ 
Table IV. Association of H. pylori and HCMV co-infection status with clinicopathological features.

\begin{tabular}{|c|c|c|c|c|c|c|c|c|}
\hline \multirow[b]{2}{*}{ Clinicopathological feature } & \multicolumn{2}{|c|}{$\mathrm{HCMV}^{+}$} & \multicolumn{2}{|c|}{$\mathrm{HCMV}^{-}$} & \multicolumn{2}{|c|}{ H. pylori ${ }^{+}$} & \multicolumn{2}{|c|}{ H.pylori } \\
\hline & H.pylori ${ }^{+/-}$ & P-value & H.pylori ${ }^{+/-}$ & P-value & $\mathrm{HCMV}^{+/-}$ & P-value & $\mathrm{HCMV}^{+/-}$ & P-value \\
\hline Tumor invasion & & 0.751 & & 0.977 & & 0.498 & & 0.340 \\
\hline $\mathrm{T} 1+\mathrm{T} 2$ & $10 / 8$ & & $9 / 8$ & & $10 / 9$ & & $8 / 8$ & \\
\hline $\mathrm{T} 3+\mathrm{T} 4$ & $24 / 16$ & & $31 / 28$ & & $24 / 31$ & & $16 / 28$ & \\
\hline Lymphatic metastasis & & 0.408 & & $0.003^{\mathrm{a}}$ & & $<0.001^{\mathrm{a}}$ & & 0.202 \\
\hline $\mathrm{N} 0+\mathrm{N} 1$ & $19 / 16$ & & $7 / 18$ & & $19 / 7$ & & $16 / 18$ & \\
\hline $\mathrm{N} 2+\mathrm{N} 3$ & $15 / 8$ & & $33 / 18$ & & $33 / 15$ & & $8 / 18$ & \\
\hline TNM stage & & 0.246 & & $0.023^{\mathrm{a}}$ & & $0.026^{\mathrm{a}}$ & & 0.245 \\
\hline $\mathrm{I}+\mathrm{II}$ & $16 / 15$ & & $9 / 17$ & & $16 / 9$ & & $15 / 17$ & \\
\hline III+IV & $18 / 9$ & & $31 / 19$ & & $18 / 31$ & & $9 / 19$ & \\
\hline
\end{tabular}

${ }^{\mathrm{a}} \mathrm{P}<0.05$. HCMV, human cytomegalovirus; H. pylori, Helicobacter pylori.

in the H. pylori $i^{+}$group. In the H. pylori ${ }^{-}$group, there were no significant associations between HCMV infection status and tumor invasion, lymphatic metastasis or TNM stage (Table IV).

Univariate and multivariate analyses based on lymphatic metastasis. The association between infection status and lymphatic metastasis was analyzed using univariate and multivariate analyses. Univariate analysis revealed that H. pylori $(\mathrm{P}=0.013)$, HCMV $(\mathrm{P}=0.002)$, tumor size $(\mathrm{P}<0.001)$, tumor invasion $(\mathrm{P}<0.001)$ and vascular invasion $(\mathrm{P}<0.001)$ were significantly associated with lymphatic metastasis (Table V). Other features exhibited no statistical significance $(\mathrm{P}>0.05)$. Additionally, H. pylori $[\mathrm{P}=0.007$; odds ratio $(\mathrm{OR})=3.51]$, tumor invasion $(\mathrm{P}=0.012 ; \mathrm{OR}=4.31)$ and vessel invasion $(\mathrm{P}=0.004$; $\mathrm{OR}=3.93)$ were independent risk factors for lymphatic metastasis, whereas HCMV $(\mathrm{P}=0.001$; $\mathrm{OR}=0.21$ ) was an independent protective factor for lymphatic metastasis, according to the multivariate logistic regression analysis (Table V).

To further clarify the association between lymphatic metastasis and co-infection, the patients were divided into $\mathrm{HCMV}^{-} / H$. pylori ${ }^{-}, \mathrm{HCMV}^{+} / H$. pylori ${ }^{-}, \mathrm{HCMV}^{-} / H$. pylori ${ }^{+}$ and $\mathrm{HCMV}^{+} / H$. pylori ${ }^{+}$groups. Univariate analysis revealed a significant association between lymphatic metastasis and different co-infection statuses $(\mathrm{P}=0.001)$. Compared with the $\mathrm{HCMV}^{-} / H$. pylori ${ }^{-}$group, neither $\mathrm{HCMV}^{+} / H$. pylori ${ }^{-}(\mathrm{P}=0.205)$ nor $\mathrm{HCMV}^{+} / H$. pylori $i^{+}(\mathrm{P}=0.622)$ were associated with lymphatic metastasis, whereas the $\mathrm{HCMV}^{-} / \mathrm{H}$. pylori ${ }^{+}$group $(\mathrm{P}=0.004)$ was a significant risk factor for lymphatic metastasis. Multivariate analysis revealed that $\mathrm{HCMV}^{-} / H$. pylori ${ }^{+}$ status was independently associated with lymphatic metastasis $(\mathrm{P}=0.005 ; \mathrm{OR}=6.00$; Table VI).

\section{Discussion}

PCR is the most widely used test in the laboratory to detect $H$. pylori infection in gastric tissues, and its positive rate is consistent with that of histopathological methods in fresh
GC tissues (21). In the present study, the $H$. pylori infection rate detected using PCR was 55.2\%, which was similar to the results of a previous study (22).

H. pylori is a pathogen recognized as a group I carcinogen by the International Agency for Research on Cancer (3). H. pylori infection is considered to progress to gastric malignancy via two different mechanisms $(22,23)$. First, the virulence factors produced by $H$. pylori, such as cytotoxin-associated gene A, directly damage the mucosa, resulting in neoplastic transformation (23). Second, $H$. pylori causes chronic inflammation; infiltration of neutrophils and lymphocytes upregulate numerous pro-inflammatory cytokines, including interleukin (IL)-1, IL-6, IL-8, tumor necrosis factor $\alpha$ and inflammation-associated transcription factors such as NF- $\kappa \mathrm{B}$ (22). These inflammation-associated factors, particularly $\mathrm{NF}-\kappa \mathrm{B}$ and IL-8, are important mediators in gastric carcinogenesis (22). H.pylori infection and consequent chronic inflammation are considered to be a major step in the occurrence and development of GC (22). In the present study, analysis of the association between $H$. pylori infection and clinicopathological features revealed that the H. pylori $i^{+}$group exhibited a higher rate of regional lymph node metastasis and a higher TNM stage. Additionally, multivariate analysis revealed that $H$. pylori infection was independently associated with lymphatic metastasis.

The study of $H$. pylori has long been the focus of GC research, although most studies $(3,20,22,23)$ have focused on $H$. pylori itself, ignoring the complicated pathogenic microbiological environment of GC and neglecting the synergistic or antagonistic effects of $H$. pylori with other pathogenic microorganisms. Increasing evidence has suggested that HCMV is detected at a very low level in various types of tumor $(12,24,25)$. For example, Cobbs et al (24) have detected HCMV genes and their products in glioblastoma multiforme (GBM). In the present study, HCMV was detected in $43.3 \%$ of patients with GC, and compared with our previous GC study (15), the results obtained using different primers exhibited improved consistency. This discrepancy may be due to improved 
Table V. Univariate and multivariate logistic regression analyses of lymphatic metastasis and infection status.

\begin{tabular}{|c|c|c|c|c|c|c|}
\hline \multirow[b]{2}{*}{ Clinicopathological feature } & \multirow[b]{2}{*}{$\mathrm{N} 0+\mathrm{N} 1$} & \multirow[b]{2}{*}{$\mathrm{N} 2+\mathrm{N} 3$} & \multicolumn{2}{|c|}{ Univariate analysis } & \multicolumn{2}{|c|}{ Multivariate analysis } \\
\hline & & & OR $(95 \% \mathrm{CI})$ & P-value & OR $(95 \% \mathrm{CI})$ & P-value \\
\hline H. pylori & & & & $0.013^{\mathrm{a}}$ & & $0.007^{\mathrm{a}}$ \\
\hline No & 34 & 26 & 1 & & 1 & \\
\hline Yes & 26 & 48 & $2.41(1.20,4.86)$ & & $3.51(1.41,8.71)$ & \\
\hline HCMV & & & & $0.002^{\mathrm{a}}$ & & $0.001^{\mathrm{a}}$ \\
\hline No & 35 & 23 & 1 & & 1 & \\
\hline Yes & 25 & 51 & $0.32(0.16,0.66)$ & & $0.21(0.08,0.53)$ & \\
\hline Sex & & & & 0.730 & & 0.759 \\
\hline Female & 17 & 19 & 1 & & 1 & \\
\hline Male & 43 & 55 & $1.14(0.53,2.46)$ & & $1.17(0.42,3.25)$ & \\
\hline Ageb, years & & & & 0.314 & & 0.825 \\
\hline$<68$ & 32 & 33 & 1 & & 1 & \\
\hline$\geq 68$ & 28 & 41 & $1.42(0.72,2.81)$ & & $1.11(0.45,2.69)$ & \\
\hline Tumor size, $\mathrm{cm}$ & & & & $<0.001^{\mathrm{a}}$ & & 0.060 \\
\hline$<5$ & 44 & 30 & 1 & & 1 & \\
\hline$\geq 5$ & 16 & 44 & $4.03(1.93,8.43)$ & & $2.44(0.96,6.16)$ & \\
\hline Tumor location & & & $1.37(0.91,2.06)$ & $0.543^{\mathrm{c}}$ & $1.12(0.67,1.85)$ & 0.669 \\
\hline Antrum & 41 & 42 & & & & \\
\hline Corpus & 10 & 14 & & & & \\
\hline Cardia & 8 & 15 & & & & \\
\hline Diffuse & 1 & 3 & & & & \\
\hline General type & & & & 0.385 & & 0.304 \\
\hline Non-ulcer & 8 & 14 & 1 & & 1 & \\
\hline Ulcer & 52 & 60 & $0.66(0.26,1.70)$ & & $0.49(0.12,1.93)$ & \\
\hline Tumor invasion & & & & $<0.001^{\mathrm{a}}$ & & $0.012^{\mathrm{a}}$ \\
\hline $\mathrm{T} 1+\mathrm{T} 2$ & 25 & 10 & 1 & & 1 & \\
\hline $\mathrm{T} 3+\mathrm{T} 4$ & 35 & 64 & $4.57(1.97,10.60)$ & & $4.31(1.38,13.40)$ & \\
\hline Vessel invasion & & & & $<0.001^{\mathrm{a}}$ & & $0.004^{\mathrm{a}}$ \\
\hline No & 47 & 34 & 1 & & 1 & \\
\hline Yes & 13 & 40 & $4.25(1.98,9.15)$ & & $3.93(1.55,9.96)$ & \\
\hline Differentiation & & & & 0.160 & & 0.221 \\
\hline Well/moderate & 17 & 11 & 1 & & 1 & \\
\hline Poor & 32 & 46 & $2.22(0.92,5.37)$ & & $2.25(0.73,6.92)$ & \\
\hline Other & 11 & 17 & $2.39(0.82,6.98)$ & & $3.24(0.79,13.22)$ & \\
\hline
\end{tabular}

${ }^{\mathrm{a}} \mathrm{P}<0.05$; ${ }^{\mathrm{b} D i v i d e d}$ into two groups based on median age; 'Calculated using Fisher's exact test. N, lymphatic metastasis; OR, odds ratio; HCMV, human cytomegalovirus; H. pylori, Helicobacter pylori.

specimen quality control, optimization of PCR conditions and quality of primers. The $\mathrm{HCMV}^{+}$specimens were mostly tumor tissues, which was consistent with studies performed in prostatic carcinoma, colorectal cancer and malignant glioma $(12,24,25)$. Similarly to previously reported PCR results (26), the detection rate of $H$. pylori in peri-tumoral tissues was higher than that in tumor tissues in the present study, suggesting that H. pylori and HCMV infections do not completely overlap spatially.

Rahbar et al (27) have demonstrated the prognostic value of the infection status of HCMV in patients with GBM. In breast cancer, HCMV proteins have been detected in sentinel lymph nodes, suggesting that HCMV may contribute to metastasis (11). A number of genes encoded by HCMV, such as UL123, UL36-38, UL97 and US28, participate in cellular transformation (28). In addition, several HCMV genes serve roles in apoptosis, cell cycle, invasion and migration of cancer cells, and angiogenesis in glioblastoma (17,28-37) Furthermore, HCMV participates in tumor immunomodulation $(38,39)$. In the present study, statistical analysis revealed that lymphatic metastasis and TNM stage were associated with a negative HCMV status. 
Table VI. Univariate and multivariate logistic regression analyses of lymphatic metastasis and co-infection status.

\begin{tabular}{|c|c|c|c|c|c|c|}
\hline \multirow[b]{2}{*}{ Clinicopathological feature } & \multirow[b]{2}{*}{$\mathrm{N} 0+\mathrm{N} 1$} & \multirow[b]{2}{*}{$\mathrm{N} 2+\mathrm{N} 3$} & \multicolumn{2}{|c|}{ Univariate analysis } & \multicolumn{2}{|c|}{ Multivariate analysis } \\
\hline & & & OR $(95 \% \mathrm{CI})$ & P-value & OR $(95 \% \mathrm{CI})$ & P-value \\
\hline Infection status & & & & $0.001^{\mathrm{a}}$ & & \\
\hline $\mathrm{HCMV}^{\prime} / H$. pylori & 10 & 12 & 1 & & 1 & \\
\hline $\mathrm{HCMV}^{+} / H$. pylori ${ }^{-}$ & 9 & 6 & $0.50(0.17,1.46)$ & $0.205^{\mathrm{b}}$ & $0.41(0.11,1.56)$ & $0.192^{\mathrm{b}}$ \\
\hline $\mathrm{HCMV}^{+} /$H. pylori ${ }^{+}$ & 9 & 11 & $0.79(0.31,2.02)$ & $0.622^{b}$ & $0.75(0.23,2.41)$ & $0.624^{\mathrm{b}}$ \\
\hline $\mathrm{HCMV}^{-} /$H. pylori ${ }^{+}$ & 4 & 20 & $4.71(1.66,13.40)$ & $0.004^{\mathrm{a}, \mathrm{b}}$ & $6.00(1.71,21.04)$ & $0.005^{\mathrm{a}, \mathrm{b}}$ \\
\hline
\end{tabular}

${ }^{\mathrm{a}} \mathrm{P}<0.05 ;{ }^{\mathrm{b}} \chi^{2}$ test vs. the $\mathrm{HCMV} / H$. pylori ${ }^{-}$group. OR, odds ratio; HCMV, human cytomegalovirus; H. pylori, Helicobacter pylori.

HCMV causes chronic inflammation similarly to other tumor-associated pathogens, such as H.pylori (40). A previous study has reported the potential interaction between HCMV and other pathogens (41). Compared with $\mathrm{HCMV}^{-} /$human papilloma virus (HPV)- cases, $\mathrm{HCMV}^{+} / \mathrm{HPV}^{+}$but not $\mathrm{HCMV}^{-} / \mathrm{HPV}^{+}$patients with cervical carcinoma had a significantly higher rate of metastasis to lymph nodes, indicating a synergetic effect between HCMV and HPV on lymphatic metastasis in cervical carcinoma (41). In the present study, analysis of the clinical significance of HCMV and $H$. pylori co-infection revealed that in the $\mathrm{HCMV}^{+}$group, $H$. pylori infection status was not associated with lymphatic metastasis. However, in the HCMV $\mathrm{H}^{-}$group, $H$. pylori infection status was significantly associated with lymphatic metastasis. In addition, the co-infection status was associated with lymphatic metastasis, and compared with the $\mathrm{HCMV}^{-} / H$. pylori group, the $\mathrm{HCMV}^{-} / H$. pylori ${ }^{+}$status was a potential risk factor for lymphatic metastasis. Multivariate analysis revealed that the $\mathrm{HCMV}^{-} / H$. pylori ${ }^{+}$status was independently associated with high level of lymphatic metastasis. Therefore, HCMV and $H$. pylori may interact in GC by exerting an antagonistic effect on lymphatic metastasis progression. These contradictory results in GC and cervical carcinoma may be associated with the complexity of the GC microenvironment and with HCMV infection itself. A recent study revealed no association between HCMV infection and lymphatic metastasis, nor the characteristics of co-infection with $H$. pylori (26). However, $65 \%$ of samples in the aforementioned study were located at the proximal position of the stomach, in contrast to the cohort in the present study in which the majority $(62 \%)$ of tumors were located at the distal position. This suggests that the role of HCMV may be associated with the tumor location in the stomach. In human malignant glioma, which is the most studied HCMV-associated tumor, HCMV infection is mainly regarded as a tumor promoter $(42,43)$. However, previous studies have revealed that HCMV may be a protective factor in the outcome of gastrointestinal tumors, breast cancer and hepatocellular carcinoma (44-47). Furthermore, the HCMV genes US28 (48) and UL123 (49) can accelerate tumor growth and enhance cancer cell stemless, while UL138 can promote the apoptosis of cancer cells (17). A recent report has revealed that in GC, low $\beta$-catenin-interacting protein 1 (CTNNBIP1) expression is associated with well-differentiated tumor grades, and CTNNBIP1 downregulation is significantly associated with HCMV infection (50), indicating a possible tumor inhibition mechanism of HCMV. The Epstein-Barr virus (EBV), which is a cancer promoter in Burkitt lymphoma and nasopharyngeal carcinoma, may also serve a protective role in GC (51-54). Several studies have demonstrated that EBV-associated GC exhibits a lower rate of lymph node metastasis $(53,54)$. These results suggest that HCMV may serve multiple roles in different types of tumor, which may be associated with its latent and proliferative status, varied tumor microenvironment, interaction with other tumor-associated pathogens, diverse immunomodulatory effects of HCMV and HCMV gene expression characteristics (51-54).

Based on the results of the present study, it can be speculated that there may be a pathway through which HCMV inhibits $H$. pylori ${ }^{+}$GC lymphatic metastasis, which may be used as a guide for clinicians when planning the patients' treatment modalities. The research on $H$. pylori mainly focuses on its carcinogenic role, since $H$. pylori is a recognized cause of GC. Eradication of $H$. pylori is an effective way to prevent GC. However, to the best of our knowledge, there is no conclusive evidence that patients with GC can benefit from eradication or non-eradication of $H$. pylori. The present results may suggest that patients with GC who are positive for both $H$. pylori and HCMV may be exempted from $H$. pylori eradication.

There were certain limitations in the current study. Only the positive rates of $H$. pylori and HCMV infection were detected, without their copy numbers, so the role of the infection level in the co-infection remains to be explored. Additionally, only PCR was used as a detection method, not supplemented by immunohistochemistry, in situ hybridization or other methods, which may affect the true positive rate of the infections.

In conclusion, the results of the present study revealed that $H$. pylori infection may increase tumor aggressiveness by promoting lymphatic metastasis. However, in patients with HCMV and $H$. pylori co-infection, $H$. pylori may lose its tumor-promoting ability, and this group of patients exhibited a lower risk of developing a high level of lymphatic metastasis. This suggests that HCMV may inhibit lymphatic metastasis through an $H$. pylori-associated pathway, which should be further investigated in future research.

\section{Acknowledgements}

Not applicable. 


\section{Funding}

The present study was supported by the National Natural Science Foundation of China (grant nos. 81472308, 81672707, 31670922 and 31470891).

\section{Availability of data and materials}

The datasets used and/or analyzed during the current study are available from the corresponding author on reasonable request.

\section{Authors' contributions}

$\mathrm{CC}$ and SC performed the experiments, analyzed and interpreted the data, and drafted the manuscript. $\mathrm{ZH}$ collected the clinical data and performed statistical analysis. WX designed the study and performed the experiments. TZ, CM, LZ and XSu collected the tissue specimens. XSh analyzed and interpreted the data, revised the manuscript and finally approved the version of the manuscript for publication. TK and XX contributed to the conception and design of the study and interpreted the data; in addition, XX supervised the study, analyzed the data, provided the project funding, revised the manuscript and finally approved the version of the manuscript for publication. All authors read and approved the final version of the manuscript.

\section{Ethics approval and consent to participate}

The study was approved by the Human Research Ethics Committee of the Second Affiliated Hospital of Wenzhou Medical University (Wenzhou, China), and written informed consent was provided by all participants.

\section{Patient consent for publication}

Not applicable.

\section{Competing interests}

The authors declare that they have no competing interests.

\section{References}

1. Torre LA, Bray F, Siegel RL, Ferlay J, Lortet-Tieulent J and Jemal A: Global cancer statistics, 2012. CA Cancer J Clin 65: 87-108, 2015.

2. Correa P, Haenszel W, Cuello C, Tannenbaum S and Archer M: A model for gastric cancer epidemiology. Lancet 2: 58-60, 1975.

3. Plummer M, Franceschi S, Vignat J, Forman D and de Martel C: Global burden of gastric cancer attributable to Helicobacter pylori. Int J Cancer 136: 487-490, 2015.

4. Peng C, Ouyang Y, Lu N and Li N: The NF- $\kappa B$ signaling pathway, the microbiota, and gastrointestinal tumorigenesis: Recent advances. Front Immunol 11: 1387, 2020.

5. Amieva M and Peek RM Jr: Pathobiology of Helicobacter pylori-induced gastric cancer. Gastroenterology 150: 64-78, 2016.

6. Dunn W, Chou C, Li H, Hai R, Patterson D, Stolc V, Zhu H and Liu F: Functional profiling of a human cytomegalovirus genome. Proc Natl Acad Sci USA 100: 14223-14228, 2003.

7. Tomtishen JP III: Human cytomegalovirus tegument proteins (pp65, pp71, pp150, pp28). Virol J 9: 22, 2012.
8. Solomon IH, Ramkissoon SH, Milner DA Jr and Folkerth RD: Cytomegalovirus and glioblastoma: A review of evidence for their association and indications for testing and treatment. J Neuropathol Exp Neurol 73: 994-998, 2014.

9. Melnick M, Sedghizadeh PP, Allen CM and Jaskoll T: Human cytomegalovirus and mucoepidermoid carcinoma of salivary glands: Cell-specific localization of active viral and oncogenic signaling proteins is confirmatory of a causal relationship. Exp Mol Pathol 92: 118-125, 2012.

10. Brouchet L, Valmary S, Dahan M, Didier A, Galateau-Salle F, Brousset $P$ and Degano B: Detection of oncogenic virus genomes and gene products in lung carcinoma. Br J Cancer 92: 743-746, 2005.

11. Taher C, de Boniface J, Mohammad AA, Religa P, Hartman J, Yaiw KC, Frisell J, Rahbar A and Söderberg-Naucler C: High prevalence of human cytomegalovirus proteins and nucleic acids in primary breast cancer and metastatic sentinel lymph nodes. PLoS One 8: e56795, 2013.

12. Samanta M, Harkins L, Klemm K, Britt WJ and Cobbs CS: High prevalence of human cytomegalovirus in prostatic intraepithelial neoplasia and prostatic carcinoma. J Urol 170: 998-1002, 2003.

13. Cai ZZ, Xu JG, Zhou YH, Zheng JH, Lin KZ, Zheng SZ, Ye MS He Y, Liu CB and Xue ZX: Human cytomegalovirus-encoded US28 may act as a tumor promoter in colorectal cancer. World J Gastroenterol 22: 2789-2798, 2016.

14. Lepiller Q, Tripathy MK, Di Martino V, Kantelip B and Herbein G: Increased HCMV seroprevalence in patients with hepatocellular carcinoma. Virol J 8: 485, 2011.

15. Zhang L, Guo G, Xu J, Sun X, Chen W, Jin J, Hu C, Zhang P, Shen X and Xue X: Human cytomegalovirus detection in gastric cancer and its possible association with lymphatic metastasis. Diagn Microbiol Infect Dis 88: 62-68, 2017.

16. Jin J, Hu C, Wang P, Chen J, Wu T, Chen W, Ye L, Zhu G, Zhang L, Xue X and Shen X: Latent infection of human cytomegalovirus is associated with the development of gastric cancer. Oncol Lett 8: 898-904, 2014.

17. Chen W, Lin K, Zhang L, Guo G, Sun X, Chen J, Ye L, Ye S, Mao C, Xu J, et al: The cytomegalovirus protein UL138 induces apoptosis of gastric cancer cells by binding to heat shock protein 70. Oncotarget 7: 5630-5645, 2016.

18. National Comprehensive Cancer Network: (NCCN) Clinical Practice Guidelines in Oncology. Gastric Cancer, Version 3.2015. https://www.nccn.org. Accessed March 25, 2015.

19. Tan MP,Kaparakis M,Galic M,Pedersen J,Pearse M, Wijburg OL, Janssen PH and Strugnell RA: Chronic Helicobacter pylori infection does not significantly alter the microbiota of the murine stomach. Appl Environ Microbiol 73: 1010-1013, 2007.

20. Tang YL, Gan RL, Dong BH, Jiang RC and Tang RJ: Detection and location of Helicobacter pylori in human gastric carcinomas. World J Gastroenterol 11: 1387-1391, 2005.

21. Fabre R, Sobhani I, Laurent-Puig P, Hedef N, Yazigi N, Vissuzaine C, Rodde I, Potet F, Mignon M, Etienne JP, et al: Polymerase chain reaction assay for the detection of Helicobacter pylori in gastric biopsy specimens: Comparison with culture, rapid urease test, and histopathological tests. Gut 35: 905-908, 1994.

22. Wang F,Meng W,Wang B andQiaoL: Helicobacterpylori-induced gastric inflammation and gastric cancer. Cancer Lett 345: 196-202, 2014.

23. Kao CY, Sheu BS and Wu JJ: Helicobacter pylori infection: An overview of bacterial virulence factors and pathogenesis. Biomed J 39: 14-23, 2016.

24. Cobbs CS, Harkins L, Samanta M, Gillespie GY, Bharara S, King PH, Nabors LB, Cobbs CG and Britt WJ: Human cytomegalovirus infection and expression in human malignant glioma. Cancer Res 62: 3347-3350, 2002.

25. Harkins L, Volk AL, Samanta M, Mikolaenko I, Britt WJ, Bland KI and Cobbs CS: Specific localisation of human cytomegalovirus nucleic acids and proteins in human colorectal cancer. Lancet 360: 1557-1563, 2002.

26. FattahiS,Nikbakhsh N,TaheriH,GhadamiE,Kosari-MonfaredM, Amirbozorgi G, Asouri M, Pilehchian-Langroudi M, Ranaee M, Samadani AA, et al: Prevalence of multiple infections and the risk of gastric adenocarcinoma development at earlier age. Diagn Microbiol Infect Dis 92: 62-68, 2018.

27. Rahbar A, Orrego A, Peredo I, Dzabic M, Wolmer-Solberg N, Strååt K, Stragliotto $G$ and Söderberg-Nauclér C: Human cytomegalovirus infection levels in glioblastoma multiforme are of prognostic value for survival. J Clin Virol 57: 36-42, 2013. 
28. Johnsen JI, Baryawno N and Soderberg-Naucler C: Is human cytomegalovirus a target in cancer therapy? Oncotarget 2 : $1329-1338,2011$.

29. Goldmacher VS, Bartle LM, Skaletskaya A, Dionne CA, Kedersha NL, Vater CA, Han JW, Lutz RJ, Watanabe S, Cahir McFarland ED, et al: A cytomegalovirus-encoded mitochondria-localized inhibitor of apoptosis structurally unrelated to Bcl-2. Proc Natl Acad Sci USA 96: 12536-12541, 1999.

30. Skaletskaya A, Bartle LM, Chittenden T, McCormick AL, Mocarski ES and Goldmacher VS: A cytomegalovirus-encoded inhibitor of apoptosis that suppresses caspase-8 activation. Proc Natl Acad Sci USA 98: 7829-7834, 2001.

31. McCormick AL, Skaletskaya A, Barry PA, Mocarski ES and Goldmacher VS: Differential function and expression of the viral inhibitor of caspase 8-induced apoptosis (vICA) and the viral mitochondria-localized inhibitor of apoptosis (vMIA) cell death suppressors conserved in primate and rodent cytomegaloviruses. Virology 316: 221-233, 2003.

32. Michaelis M, Kotchetkov R, Vogel JU, Doerr HW and Cinatl J Jr: Cytomegalovirus infection blocks apoptosis in cancer cells. Cell Mol Life Sci 61: 1307-1316, 2004.

33. McCormick AL: Control of apoptosis by human cytomegalovirus. Curr Top Microbiol Immunol 325: 281-295, 2008.

34. Moorman NJ, Cristea IM, Terhune SS, Rout MP, Chait BT and Shenk T: Human cytomegalovirus protein UL38 inhibits host cell stress responses by antagonizing the tuberous sclerosis protein complex. Cell Host Microbe 3: 253-262, 2008.

35. Norris KL and Youle RJ: Cytomegalovirus proteins vMIA and $\mathrm{m} 38.5$ link mitochondrial morphogenesis to $\mathrm{Bcl}-2$ family proteins. J Virol 82: 6232-6243, 2008.

36. Michaelis M, Doerr HW and Cinatl J: The story of human cytomegalovirus and cancer: Increasing evidence and open questions Neoplasia 11: 1-9, 2009.

37. Soroceanu L, Matlaf L, Bezrookove V, Harkins L, Martinez R, Greene M, Soteropoulos P and Cobbs CS: Human cytomegalovirus US28 found in glioblastoma promotes an invasive and angiogenic phenotype. Cancer Res 71: 6643-6653, 2011.

38. Foster H, Ulasov IV and Cobbs CS: Human cytomegalovirusmediated immunomodulation: Effects on glioblastoma progression Biochim Biophys Acta Rev Cancer 1868: 273-276, 2017.

39. Guo G, Ye S, Xie S, Ye L, Lin C, Yang M, Shi X, Wang F, $\mathrm{Li} \mathrm{B}, \mathrm{Li} \mathrm{M}$, et al: The cytomegalovirus protein US31 induces inflammation through mono-macrophages in systemic lupus erythematosus by promoting NF-KB2 activation. Cell Death Dis 9: 104, 2018

40. Soroceanu L and Cobbs CS: Is HCMV a tumor promoter? Virus Res 157: 193-203, 2011.

41. Chen TM, Chang CF, Chen YH, Chen CA, Wu CC and Hsieh CY: Coexistence of human cytomegalovirus and human papillomavirus type 16 correlates with lymph node metastasis in cervical cancer. J Cancer Res Clin Oncol 122: 629-632, 1996.

42. Hortal AM, Vermeulen JF, Van Hecke W and Bovenschen N: Oncogenic role of cytomegalovirus in medulloblastoma? Cancer Lett 408: 55-59, 2017

43. Joseph GP, McDermott R, Baryshnikova MA, Cobbs CS and Ulasov IV: Cytomegalovirus as an oncomodulatory agent in the progression of glioma. Cancer Lett 384: 79-85, 2017.
44. Chen HP, Jiang JK, Chen CY, Yang CY, Chen YC, Lin CH, Chou TY, Cho WL and Chan YJ: Identification of human cytomegalovirus in tumour tissues of colorectal cancer and its association with the outcome of non-elderly patients. J Gen Virol 97: 2411-2420, 2016.

45. Oberstein A and Shenk T: Cellular responses to human cytomegalovirus infection: Induction of a mesenchymal-to-epithelial transition (MET) phenotype. Proc Natl Acad Sci USA 114: E8244-E8253, 2017.

46. Kumar A, Coquard L, Pasquereau S, Russo L, Valmary-Degano S, Borg C, Pothier P and Herbein G: Tumor control by human cytomegalovirus in a murine model of hepatocellular carcinoma. Mol Ther Oncolytics 3: 16012, 2016.

47. Erkes DA, Wilski NA and Snyder CM: Intratumoral infection by CMV may change the tumor environment by directly interacting with tumor-associated macrophages to promote cancer immunity. Hum Vaccin Immunother 13: 1778-1785, 2017.

48. Heukers R, Fan TS, de Wit RH, van Senten JR, De Groof TWM, Bebelman MP, Lagerweij T, Vieira J, de Munnik SM, Smits-de Vries L, et al: The constitutive activity of the virally encoded chemokine receptor US28 accelerates glioblastoma growth. Oncogene 37: 4110-4121, 2018.

49. Soroceanu L, Matlaf L, Khan S, Akhavan A, Singer E, Bezrookove V, Decker S, Ghanny S, Hadaczek P, Bengtsson H, et al: Cytomegalovirus immediate-early proteins promote stemness properties in glioblastoma. Cancer Res 75: 3065-3076, 2015.

50. Kosari-Monfared M, Nikbakhsh N, Fattahi S, Ghadami E, Ranaei M, Taheri H, Amjadi-Moheb F, Godazandeh GA, Shafaei S, Pilehchian-Langroudi M, et al: CTNNBIP1 downregulation is associated with tumor grade and viral infections in gastric adenocarcinoma. J Cell Physiol 234: 2895-2904, 2019.

51. Camargo MC, Kim WH, Chiaravalli AM, Kim KM, Corvalan AH, Matsuo K, Yu J, Sung JJ, Herrera-Goepfert R, Meneses-Gonzalez F, et al: Improved survival of gastric cancer with tumour Epstein-Barr virus positivity: An international pooled analysis. Gut 63: 236-243, 2014.

52. Shinozaki-Ushiku A, Kunita A and Fukayama M: Update on Epstein-Barr virus and gastric cancer (review). Int J Oncol 46: 1421-1434, 2015.

53. Yanagi A, Nishikawa J, Shimokuri K, Shuto T, Takagi T, Takagi F, Kobayashi Y, Yamamoto M, Miura O, Yanai H, et al: Clinicopathologic characteristics of epstein-barr virus-associated gastric cancer over the past decade in Japan. Microorganisms 7: 305,2019

54. Osumi H, Kawachi H, Yoshio T, Ida S, Yamamoto N, Horiuchi Y, Ishiyama A, Hirasawa T, Tsuchida T, Hiki N, et al: Epstein-Barr virus status is a promising biomarker for endoscopic resection in early gastric cancer: Proposal of a novel therapeutic strategy. J Gastroenterol 54: 774-783, 2019.

This work is licensed under a Creative Commons Attribution-NonCommercial-NoDerivatives 4.0 International (CC BY-NC-ND 4.0) License. 